\title{
MOTOR INTERVENTION IN CHILDREN WITH SCHOOL LEARNING DIFFICULTIES
}

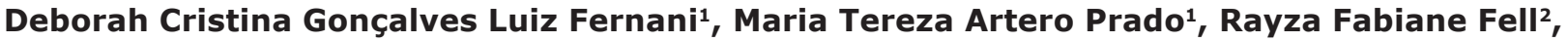 \\ Nelline Largueza dos Reis², Tânia Cristina Bofí2, Eliane Beraldi Ribeiro ${ }^{3}$, \\ Márcia de Toledo Blake ${ }^{4}$, Carlos Bandeira de Mello Monteiro ${ }^{4,5}$
}

\begin{abstract}
This study sought to evaluate motor development in children aged 6 to 11 years with learning difficulties and school characteristics of delayed motor development, before and after application of a motor intervention program. The sample consisted of 28 children with a mean age of $107.21 \pm$ 16.56 months, who were evaluated by the Motor Development Scale and received motor intervention for 6 months, followed by reassessment. We observed a statistically significant difference between the average of the motor activity ratios in all areas of the evaluation and reevaluation. Also verified in the evaluation were the concentration ratios of children with motor activity greater than or equal to 80 and there was a revaluation increase in this concentration on re-evaluation, the areas with the greatest increase in concentration and significant differences being: Body Schema, Space and temporal Organization. In the overall evaluation of MDS, most children presented the classification of "low normal". However, in the reassessment most have evolved into the "average normal", only 4 of themremaining in the same classification. Therefore, in this study, children with learning disabilities also showed motor deficits and the intervention applied contributed to an increase in the motor ratios with consequent improvement in motor development. Besides psychopedagogical asistance, it is essential to reassess them and if necessary apply the intervention in the motor development of children with learning difficulties.
\end{abstract}

Key words: child development; intervention; learning.

\section{Introduction}

Motor development refers to the gradual acquisition of motor functions, being influenced by cognitive and affective domains ${ }^{1}$. The changes in motor development are characterized by deficits in several areas such as: fine motor, overall balance, body schema and spatial-temporal organization.

Children who have major problems in academic skills are children with learning disabilities ${ }^{2}$, that can be perceived by the lower than expected academic performance Schema. These children have deficits in one or more domains of academic achievement, such as reading disorders, mathematical disorders, and/or disorders of written expression ${ }^{3}$.

Both motor development and learning difficulties relate to the chronological age of the child and can be detected in everyday school activities ${ }^{4.5}$. In addition, children with learning deficits generally have poor gross motor skills compared to their typically developing peers ${ }^{6}$.

Changes in motor response in children are found in medical diagnoses for attention-deficithyperactivity disorder $(A D H D)^{7.8}$, autism spectrum disorders ${ }^{9}$ and dyslexia ${ }^{10}$. The terminology Developmental Coordination Disorder (DCD) ${ }^{11}$ is now widely used as is the interesting designation of children with probable developmental Coordination disorder, with more detail in the study carried out by Lingam et al. (2010) ${ }^{12}$, which sought to explore associations between that developmental coordination disorder and attention, language, social skills, and academic ability in a population-based cohort.

The detection of changes in motor development has the function of enabling one to know the

\footnotetext{
1 Laboratório de Escrita Científica da Faculdade de Medicina do ABC, Santo André/SP; Universidade do Oeste Paulista, Presidente Prudente/SP.

2 Faculdade de Ciências e Tecnologia da Universidade Estadual Paulista, Presidente Prudente/SP.

3 Departamento de Fisiologia e Fisiopatologia da Nutrição, Universidade Federal de São Paulo, São Paulo/SP.

4 Laboratório de Escrita Científica da Faculdade de Medicina do ABC, Santo André/SP.

5 Escola de Artes, Ciências e Humanidades da Universidade de São Paulo, São Paulo/SP.

Study carried out at Universidade do Oeste Paulista, Pres. Prudente/SP.

Corresponding author: deborah@unoeste.br
}

Suggested citation: Fernani DCGL, et al. Motor intervention in children with school learning dificulties; Journal of Human Growth and Development 2013; 23(2): 209-214

Manuscript submitted Oct 15 2012, accepted for publication Mai 022013. 
child's motor limitations and restrictions, to propose a possible solution, making adjustments in the educational program including interventions with health professionals, so that the child can reach its full potential ${ }^{13}$. Early childhood is a critical period in ontogeny, and early physical, cognitive, and socioemotional growth constitutes foundation of future development. In consequence, disabilities sustained in early childhood can have lasting effects ${ }^{14}$.

However, besides the changes, disturbances or disorders diagnosed by doctors, there are children who have learning difficulties in some motor talkes in everyday actvities witch can be detected by the observation. In those cases where there is no medical diagnosis of developmental coordination disorder, they ould be considered clumsiness ${ }^{15}$.

According to Laszlo et al. (1993) ${ }^{15}$, clumsiness is the label that describes the inability to learn or perform motor skills at a level expected for the age of the child. Thus the primary symptoms of clumsiness are inadequate performance of such skills as drawing, writing, needlework, woodwork, handling cutlery, dressing, playing ball games, bicycle riding, and running ${ }^{15}$.

Thus, regardless of the name, it appears that some children are indicated for intervention programs, for preventive purposes also, since the motor assistance seeks to stimulate cognitive development by movement, which contributes to the neuronal plasticity process in the nervous system.

Generally this need, even without medical diagnosis, appears at school and in the family that encourage and support the process of motor intervention ${ }^{16}$. For this, and in an attempt to undertak a more functional intervention, the proposed programs are dynamic and facilitated when using toys and games as coadjutants, thus allowing a greater interaction between the child, the agent and the environment, which benefits the motor development ${ }^{17}$. Through the act of playing the child can organize and modify attitudes and behaviors, which creates new learning pathways ${ }^{18,19}$.

After these opening remarks, and according to Silva et al. (2012) ${ }^{20}$, there is a need for further studies related to the incidence and prevalence of physical and learning disabilities in Brazilian children, since this phenomenon is still unknown to the general population, which means that children who have such disabilities do not receive appropriate treatment.

Therefore, the aim of this study was to evaluate the motor development of children and verify the effectiveness of motor intervention aged 6 to 11 years, would be benefitted by even when they had no medical diagnosis of any motor or cognitive disability but who had learning difficulties at school and characteristics of delayed motor development observed by teachers.

\section{METHODS}

This study was previously approved by the Ethics Committee of the University of Oeste Paulista, UNOESTE (protocol No. 160/07). The sample consisted of children with learning difficulties at school, subjectively identified by teachers with low performance in the disciplines offered and similar features of motor clumsiness, since the children did not have all the features suggested by Laszlo et al. $(1993)^{15}$ : inadequate performance in such skills as drawing, writing, needlework, woodwork, handling cutlery, dressing, playing ball games, bicycle riding, and running, other symptoms suchas personal and interpersonal problems such as low self-esteem, lack of confidence, and social withdrawal were also considered.

All the children evaluated were enrolled in public schools, located in the city of Presidente Prudente/SP.

Children with any medical diagnosis with alteration in the central or peripheral nervous system, or diagnosis of attention-deficithyperactivity disorder, autism spectrum disorders, dyslexia, developmental coordination disorder, physical, cognitive, hearing, visual and/or multiple character disabilities, diagnosed clinically or by specific tests by the child's physician were excluded from this study.

Initially the children were assessed using the Motor Development Scale (MDS) described by Rosa Neto $(2002)^{21}$, that evaluates the areas of Fine motricity, Global motricity, Balance, Body schema, Spatial organization and Temporal organization.

According to Goulardins et al. (2013) ${ }^{22}$, the MDS includes specific tasks designed for specific ages, ranging from 2 to 11 years, and its complexity increases with age. The MDS provides values for motor quotients (test results that are expressed in months in each test, divided by chronological age, and multiplied by 100). General Motor Quociente (GMQ) is obtained by the division of the average of test results that are expressed in months by chronological age and multiplied by one hundred 22 . The result for the general motor quotient refer to specific ranges, which classify respective levels of motor development, "very high" (equal to or up to 130 points), "high" (120 to 129), "normal high" (110 to 119), "normal medium" (90 to 109), "normal low" (80 to 89), "low" (70 to 79) and "very low" (equal to or below 69) ${ }^{21}$.

To analyze the results of this research, we used the motor quotient of each area and the overall. And it is considered that the values of the motor ratios greater than or equal to 80 , are considered to indicate that the development of the area is typical or better than expected for the chronological age and values lower than 80 mean motor deficits. However, people who have values of 80 to 89 , are already subject to motor intervention to prevent worsening and evolution of motor development. 
After the initial evaluation a motor intervention was applied to the group for a period of six months, once a week for one hour. The sessions consisted of diverse recreational games and exercises such as: moving forwards and backwards in a circular tunnel of fabric, jumping at the command office voice associated with palms inside, outside, on the one side and on the other of the hula hoop placed on the floor; living dead joke; associating sounds (clapping, whistling) with actions such as sitting, squatting, standing on one-leg support, playing hopscotch, painting and draw on, using play dough, playing statue; jump one foot; exercises that link parts of the body using music with different rhythms. At the end of the intervention period, a was reassessment made of the motor development of these children by applying the same instrument (MDS).

Prior to statistical analysis, the assumption of the normality of data was checked by the Kolmogorov-Smirnov test, whereby it was found that all the variables presented parametric distribution $(p<0.10)$. To determine whether the means of the parameters studied differed between the first and second evaluation, we used the t test for paired samples ${ }^{23}$. The frequencies of children with scores $>$ 80.0 (greatty superior, superior, high-normal, normal and low normal average) obtained in both evaluations were compared using MacNemar's chi-squared test with a continuity correction. All analyses were conducted with the aid of Biostat 5,0 software ${ }^{24}$. The level of significance was set at $5 \%$.

\section{RESULTS}

The sample comprised 28 children, 11 males and 17 females, with a mean age of $107.21 \pm 16.56$ months. The data collected showed a statistically significant difference between the average of the motor ratios of each area, the general motor quotient in the assessment and reassessment (Table 1 ).

Table 1: Values of Motor Quotients of children before and after intervention, expressed by mean and standard deviation

\begin{tabular}{cccccc}
$\begin{array}{c}\text { Parameter of } \\
\text { Motor Quotients }\end{array}$ & \multicolumn{2}{c}{ Assessment } & \multicolumn{2}{c}{ Reassessment } \\
mean & s.d. & 9.22 & 98.44 & 15.14 & s.d. \\
Fine Motricity & 90.61 & 9.00 & 101.04 & 8.83 & $<.0072^{*}$ \\
Global Motricity & 92.27 & 11.81 & 97.43 & 10.68 & $0.0001^{*}$ \\
$\quad$ Balance & 87.16 & 13.05 & 94.61 & 12.56 & $0.0011^{*}$ \\
Body Schema & 85.53 & 12.2 & 94.19 & 10.15 & $<0.0001^{*}$ \\
Spatial Organization & 83.90 & 8.56 & 100.66 & 13.44 & $<0.0001^{*}$ \\
Temporal Organization & 83.90 & 6.63 & 97.73 & 7.71 & $<0.0001^{*}$
\end{tabular}

p.d. = standard deviation; $*=p<0.001$

Table 2 shows the assessment of the concentration of children with motor quotients greater than or equal to 80 and an increase in the revaluation of this concentration, and the motor ratios corresponding to the areas of Body Schema, Space and Temporal Organization presented significant differences and had the highest increase in concentration compared with the other areas.

Table 2: Proportion of children at two different times (assessment and reassessment) according to the greater motor quotients, less than or equal to 80 and statistical significance of the chi-square by MacNemar ( $p$ ).

\begin{tabular}{|c|c|c|c|c|c|}
\hline \multirow{2}{*}{$\begin{array}{c}\text { Parameter of Motor } \\
\text { Quotients }\end{array}$} & \multicolumn{2}{|c|}{ Assessment } & \multicolumn{2}{|c|}{ Reassessment } & \multirow[b]{2}{*}{ p } \\
\hline & $>80.0$ & $\leq \mathbf{8 0 . 0}$ & $>80.0$ & $\leq \mathbf{8 0 . 0}$ & \\
\hline Fine Motricity & $85.71 \%$ & $14.29 \%$ & $85.71 \%$ & $14.29 \%$ & 1.000 \\
\hline Global Motricity & $96.43 \%$ & $3.57 \%$ & $100 \%$ & $0 \%$ & 1.000 \\
\hline Balance & $82.14 \%$ & $17.86 \%$ & $100 \%$ & $0 \%$ & 0.062 \\
\hline Body Schema & $67.86 \%$ & $32.14 \%$ & $96.43 \%$ & $3.57 \%$ & $0.007 *$ \\
\hline Spatial Organization & $60.71 \%$ & $39.29 \%$ & $96.43 \%$ & $3.57 \%$ & $0.001 *$ \\
\hline Temporal Organization & $67.86 \%$ & $32.14 \%$ & $96.43 \%$ & $3.57 \%$ & $0.007 *$ \\
\hline General Motor Quocient & $96.43 \%$ & $3.57 \%$ & $100.00 \%$ & $0 \%$ & 1.000 \\
\hline
\end{tabular}

$*=p<0.01$

In the general classification of MDS performed individually in the assessment, most children showed motor development classified as "low normal". However, althrough in the reassessment only 4 of those had not evolved and continued to be classified as "low normal", most changed to "average normal" (Table 3). 
Table 3: Distribution of children according to the classification of MDS

\begin{tabular}{|c|c|c|}
\hline \multirow[b]{2}{*}{ Classification } & \multicolumn{2}{|c|}{ Proportion (n) } \\
\hline & Assessment & Reassessment \\
\hline Very High & 0 & 0 \\
\hline High & 0 & $3.57 \%(1)$ \\
\hline Normal High & $3.57 \%(1)$ & $3.57 \%(1)$ \\
\hline Normal Medium & $21.42 \%(6)$ & $78.57 \%(22)$ \\
\hline Normal Low & $71.42 \%(20)$ & $14.28 \%(4)$ \\
\hline Low & $3.57 \%(1)$ & 0 \\
\hline
\end{tabular}

$\mathrm{n}=$ number of children

\section{DISCUSSION}

It is important to emphasize that the participants in this study underwent medical evaluation without any established diagnosis, so it the results permit the verification of the fad that the Motor Quotients of all areas represented by the mean (Table 1) are above 80 indicating normality. This means that these are children with no significant changes but who have called the attention of teachers and parents because they have different movements and poor school performance. In Table 2, instead of considering the average there was the proportion of children under 80 , one realizes that the body schema items, spacial and temporal organization more than $30 \%$ of the children are below $80 \%$. Despite initial data suggest normality in the values, parents, teachers and therapists opted to indicate clinical intervention. Thus, this study is proposed to verify whether children who performed tasks in connection with motor development, even with normal data improved their performance after intervention.

In this study we observed a significant difference of the Motor Quotient means of all areas and the General Motor Quotient of MDS compared before and after motor intervention (assessment and reassessment), which demonstrates changes in behavior after the intervention. In the evaluation, we have also found the concentration of children who had motor ratios greater than 80 in all areas and there was a revaluation increase in this concentration. In addition to checking following intervention the progress of the sample in the overall motor development by MDS, it also shows the evolution of this motor sample.

For this research The Motor Development Scale (MDS), described by Rosa Neto (2002) ${ }^{21}$, was used to assess fine and global motricity, balance, body scheme and spatial and temporal organization. Although not widely used in international studies, Goulardins et al. (2011 and 2013) 22,25 used to assess children with attention deficit hyperactivity disorder with interesting results characterizing the motor development of the group evaluated.

According to Piek JP et al. (2010) ${ }^{26}$ a quick and effective screening tool to Identify motor impairment in children that is also reliable and valid would be helpful in clinical practice and in large research studies where individual assessment is costly and time-consuming, which justifies the choice of the instrument (MDS) used in this study.

When considering school learning, Shapiro et al. $(2009)^{27}$ reports despite the wealth of research on predictors of literacy, we still have not developed clear and consistent methods for assessing literacy within the classroom. Since there is no single test available for assessing all aspects of literacy development, teachers concerned about pupils' reading difficulties require a thorough understanding of current theory in order to select suitable assessments and interpret the findings. Thus, despite the importance of the correlation between changes in motor development and school learning, few studies correlate this theme.

In a survey that compared the gross motor skills of 7 to 12 -years-old children with learning disabilities with those of age-matched typically developing children, found that children with learning disabilities scored poorer on both the locomotor and object-control subtests than their typically developing peers, and in children with learning disabilities a specific relationship was observed between reading and locomotor skills and a trend was found for a relationship between mathematics and object control skills: the larger children's learning lag, the poorer their motor skill scores. This study also stresses the importance of specific interventions facilitating both motor and academic abilities².

Their Typically Developing peers, and learning disabilities in children with a specific relationship between reading and was Observed locomotor skills and a trend was found for the relationship between mathematics and object control skills: the larger children's learning lag, the Poorer Their motor skill scores. This study also stresses the Importance of specific interventions Facilitating boths motor and academic abilities ${ }^{2}$.

Silva et al. (2012) ${ }^{20}$ in their study, identified the motor and learning difficulties in students with low academic performance. Likewise conducted in this research, the selection of participants occurred through the suggestion of teachers, pupils who had a history of poor academic performance during the semester and then used the School Performance 
Test to reaffirm learning disabilities. It was found that there was agreement between the results and initial indication of the teachers, as almost all pupils had learning difficulties, especially in reading and writing, as well as a representative number of students indicating they had motor difficulties. A significant number of children presented together with an indication of learning difficulties, problems with motor coordination. And it was suggested in his study to conduct research that will explore both the identification of developmental difficulties, and programs aimed at stimulating the economic wellbeing, quality of life and health of children with learning and motor disabilities.

Not only do these children often fail to reach their full potential, but the time and effort of teachers dealing with this problem, often unsuccessfully, and the disruption to family life, must also be considered ${ }^{15}$. Probably the difficulty in learning can also influence the school adaptation and causing frustration in the child, in accord with the developmental psychopathology model, maladaptation was conceptualized as persistent behavioral problems across diverse, routine classroom situations. It was hypothesized that socially negative behavior problems and withdrawn classroom behavior, assessed early in the Head Start year, would be associated with later disruptions in children's ability to engage in positive peer play and instructional activities ${ }^{28}$.

The evolution of motor development presented in this research during reassessment by increasing QM, by increasing the concentration of children with QM greater than 80 and increasing the number of children with MDS classification above Medium Normal, were also found in other studies, as reported by Riethmuller et al. (2009) ${ }^{29}$ in their systematic review in which $90 \%$ of the studies published which were part of the study, were efficacious in Improving motor development; approximately $47 \%$ of these reported statistically significant findings.

Rintala et al. (1998) ${ }^{30}$ compared to the efectiveness of two approaches to movement intervention: psychomotor training and regular physical education lessons, for children with a combination of language and movement difficulties. All children regardless of the type of intervention, made progress, the diferences between these two approaches were small, the children in the psychomotor training programme did improve more than those who followed the regular physical education. This fact highlights the importance of motor intervention to improve motor development.

As shown above, this study presented a significant difference between the concentration of children with motor ratios greater than or equal to 80 in the evaluation and reevaluation, in the areas of body scheme, spatial and temporal organization, and these were the ones with the smallest proportion of children with greater than 80 QM evaluation and also those that had the largest increase in concentration in the revaluation, which enables us to see further progress of the children in these areas.

The improvement in spatial and temporal organization can be associated to the evolution of body schema, thus it is important to note that the body is the reference point for humans meet and interact with the world and serve as a basis for learning important concepts for literacy. First the child visualizes these concepts through his body and then can view them on objects ${ }^{31}$.

According to Rosa Neto et al. (2010) ${ }^{13}$, the practice of motor education at school has a positive influence on motor development of children with learning difficulties such as attention, writing, reading, socializing and calculation. These children should be followed to achieve the best of their potential, because not only do these children often fail to reach their full potential, but the time and effort of teachers dealing with this problem, often unsuccessfully, and the disruption to family life, must also be considered ${ }^{15}$. According to a developmental psychopathology perspective, children's developmental trajectories are influenced by early patterns of adjustment. All children have the potential to set out on a positive developmental course; however, early difficulties place children at risk for future problems ${ }^{28}$.

Therefore, it is considered that the motor monitoring of these children at school age is a preventive attitude for professionals involved with learning.

This work presents some limitations that should be considered: (1) the subjective identification of the evaluated group through the selection of pupils with learning difficulties and developmental delay without a defined medical diagnosis seems pretty subjective, but one must consider that it is the case of several children at school in the regular school system, (2) the lack of a control group that was not organized by ethical issues and longitudinal monitoring of children could show whether there is a need for intervention in children who have subjective delays in development.

\section{CONCLUSIONS}

Therefore, in this study, children with learning difficulties and identified motor delay by regular school teachers, showed low levels of normality, and the applied motor intervention contributed to the increase in the motor ratios. It is suggested that in addition to psychopedagogic assistance, it is interesting to assess and if necessary the motor development intervention of in children with learning difficulties.

\section{ACKNOWLEDGEMENTS}

To the University of Oeste Paulista (UNOESTE) which provided a grant for the research. 


\section{REFERENCES}

1. Gallahue DL, Ozmun JC. Compreendendo o desenvolvimento motor: bebês, crianças, adolescentes e adultos. São Paulo: Phort; 2005.

2. Westendorp M, Hartman E, Houwen S, Smith J, Visscher $\mathrm{C}$. The relationship between gross motor skills and academic achievement in children with learning disabilities. Research in Developmental Disabilities. 2011; 32: 2773-79.

3. American Psychiatric Association. Diagnostic and statistical Manual of Mental Disorders IVTR (DSM-IV-TR). Washington, DC: American Psychiatric Association; 2000.

4. Carboni-Román A, del Río Grande D, Capilla A, Maestú F, Ortiz T. Bases neurobiológicas de las dificultades de aprendizaje. Rev Neurol. 2006; 42(2): 171-5.

5. Millá MG. Atención temprana de las dificultades de aprendizaje. Rev Neurol [periódico online]. 2006 [acesso em 12 Jun 2009]; 42(2): 153-6. Disponível em: http://www.revneurol.com/sec/ resumen.php? id $=2005821$.

6. Woodard RL, SurburgPR. The performance of fundamental movement skills by elementary school children with learning disabilities. The Physical Educator. 2001; 58: 198-206.

7. Casaseca-de-la-Higuera $P$, Martin-Martinez D, Alberola-Lopez S, Maria Andres-de-Llano J, Antonio Lopez-Villalobos J, RamonGarmendia Leiza J, et al. Automatic diagnosis of ADHD based on multichannel nonlinear analysis of actimetry registries. Conf Proc IEEE Eng Med Biol Soc. 2012; 4204-7.

8. Okuda PM, Pinheiro FH, Germano GD, Padula NA, Lourencetti MD, Santos LC, et al.Fine motor, sensory and perceptive function of students with attention deficit disorder with hyperactivity. J Soc Bras Fonoaudiol. 2011 Dec;23(4):351-7.

9. Narzisi A, Calderoni S, Maestro S, Calugi S, Mottes E, Muratori F. Child Behavior Check List $1 \frac{1}{2}-5$ as a tool to identify toddlers with Autism Spectrum Disorders: A case-control study. Res Dev Disabil. 2013 Jan 31;34(4):1179-89.

10. Stoodley CJ, Stein JF. Cerebellar Function in Developmental Dyslexia. Cerebellum. 2012 Aug 1.

11. Chia LC, Licari MK, Guelfi KJ, Reid SL. A comparison of running kinematics and kinetics in children with and without developmental coordination disorder. Gait Posture. 2012 Dec 21.

12. Lingam R, Golding J, Jongmans MJ, Hunt LP, Ellis $M$, Emond $A$. The association between developmental coordination disorder and other developmental traits. Pediatrics. 2010 Nov;126(5): e 1109-18.

13. Rosa Neto F, Santos APM, Xavier RFC, Amaro KN. A Importância da avaliação motora em escolares: análise da confiabilidade da Escala de Desenvolvimento Motor. Rev Bras Cineantropom Desempenho Hum. 2010, 12(6):422-7.

14. Bornstein $M H$, Hendricks $C$. Screening for developmental disabilities in developing countries. Soc Sci Med. 2012 Dec 14.
15. Laszlo JI, Sainsbury KM. Perceptual-motor development and prevention of clumsiness. Psychol Res. 1993;55(2):167-74.

16. Oliveira GC. Avaliação psicomotora à luz da psicologia e da psicopedagogia. Petrópolis: Vozes; 2008.

17. Bee H. A criança em desenvolvimento. Porto Alegre: Artmed; 2003.

18. Reis LA, Sampaio LS, Reis LA, Silva PD, Oliveira TS. O uso do lúdico e do simbólico na paralisia cerebral. Rev Saúde Com. 2007 [acesso em 16 Nov 2008]; 3(2): 10-8. Disponível em: http:// www.uesb.br/revista/rsc/v3/v3n2a02.pdf.

19. Piazera QCC, Costa KC. A importância do brincar no desenvolvimento psicomotor. Rev Divulgação Técnico-científica do ICPG. 2004; 2(6): 47-50.

20. Silva J, Beltrame TS, Oliveira AVP, Sperandio FF. Motor and learning disabilities in school children with low academic performance. J. Hum. Growth Dev. 2012; 22(1): 41-6.

21. Rosa Neto F. Manual de avaliação motora. Porto Alegre: Artmed; 2002.

22. Goulardins JB, Marques JC, Casella EB, Nascimento RO, Oliveira JA. Motor profile of children with attention deficit hyperactivity disorder, combined type. Res Dev Disabil. 2013 Jan; 34(1):40-5.

23. Pagano M, Gauvreau K. Princípios de bioestatística. 2 ed. São Paulo: Pioneira Thomson Learneing; 2004.

24. Ayres M, Ayres júnior M, Ayres DL, Santos AA. BIOESTAT - Aplicações estatísticas nas áreas das ciências bio-médicas. Belém: Ong Mamiraua; 2007.

25. Goulardins JB, Marques JC, Casella EB. Quality of life and psychomotor profile of children with attention deficit hy peractivity disorder (ADHD). Arq Neuropsiquiatr. 2011 Aug; 69(4): 630-5.

26. Piek JP, Barrett NC, Dyck MJ, Reiersen AM.Can the Child Behavior Checklist be used to screen for motor impairment? Dev Med Child Neurol. 2010 Feb;52(2):200-4.

27. Shapiro LR, Hurry J, Masterson J, Wydell TN, Doctor E. Classroom implications of recent research into literacy development: from predictors to assessment. Dyslexia. 2009 Feb;15(1):1-22.

28. Fantuzzo JW, Bulotsky-Shearer R, Fusco RA, McWayne CM. An investigation of preschool classroom behavioral djustment problems and social-emotional school readiness competencies. Early Childhood Research Quarterly. 2005; 20: 259-75.

29. Riethmuller AM, Jones RA, Okely AD. Efficacy of Interventions to Improve Motor Development in Young Children: A Systematic Review. Pediatrics. 2009; 124: e782-93.

30. Rintala P, Pienimaki K, Ahonen T, Cantell M, Kooistra $L$. The efects of a psychomotor training programme on motor skill development in children with developmental language disorders. Human Movement Science. 1998; 17: 721-37.

31. Oliveira GC. Psicomotricidade: educação e reeducação num enfoque psicopedagógico. Petrópolis: Vozes; 2007. 